\title{
Os Empreiteiros de Obras Públicas e o Golpe CiviL de 1964
}

\author{
Contractors of Public Works AND the 1964 CiVIL-Military Coup \\ Pedro Henrique Pedreira Campos* \\ phpcampos@yahoo.com.br
}

\begin{abstract}
RESUMO: Passadas três décadas do fim do governo do último general-ditador, a sociedade brasileira ainda guarda muitas marcas que remontam ao período do regime autoritário. Uma delas é o fato de vários grupos empresariais que dominam hoje a economia e, em certa medida, também a política brasileira, terem crescido de maneira significativa ao longo da ditadura. Dentre esses empresários, os empreiteiros de obras públicas se destacam, sendo que sua importância atual na economia brasileira remete em grande parte à emergência verificada no período ditatorial, quando as empresas do setor foram beneficiadas por políticas altamente favoráveis e cresceram de forma expressiva. Antes disso, e tendo relação direta com essas políticas benéficas, os empreiteiros desempenharam um papel bastante ativo no golpe de Estado de 1964. Nossa intenção nesse artigo é tentar apreender o posicionamento e a contribuição desse fração específica do empresariado brasileiro no golpe civilmilitar.
\end{abstract}

PALAVRAS-CHAVE: Empreiteiros de obras públicas; Golpe civil-militar de 1964; Empresariado brasileiro.

ABSTRACT: Three decades after the end of the last general-dictator government, Brazilian society still has many brands that date back to the period of authoritarian rule. One is the fact that several business groups that now dominate the economy and, to some extent,also the Brazilian politics, have grown significantly under the dictatorship. Among these entrepreneurs, the contractors of public works stand out, and its current importance in the Brazilian economy refers largely to the emergence observed in the dictatorial period, when companies of the sector have benefited from highly favourable policies and grew significantly. Before that, and having a direct relationship with these beneficial policies, contractors played a very active role in the coup of 1964. Our intention in this paper is to grasp the position and the contribution of these specific fraction of the Brazilian business in civil - military coup.

KEYWORDS: Contractors; 1964 Civil-military coup, Brazilian businessmen.

\section{Introdução}

\footnotetext{
* Doutor em História Social pela UFF e professor do Departamento de História e Relações Internacionais da UFRRJ.
} 
Não é novidade que alguns grupos econômicos foram intensamente beneficiados pela ditadura brasileira (1964-1988). No movimento de aprofundamento e extensão do processo de acumulação capitalista no Brasil verificado no período, empresas brasileiras e estrangeiras de setores como comunicações, indústria e finanças foram fartamente favorecidas pelas políticas públicas adotadas após o golpe de Estado e conseguiram se consolidar como grandes grupos, inclusive se posicionando na forma de oligopólio ou monopólio em seus setores de atuação.

Ao lado de outros ramos da economia brasileira, a construção civil percebeu uma ascensão inédita no período. No interior desse setor industrial, a construção pesada, que abrange as empresas dedicadas às obras públicas de infra-estrutura - as empreiteiras -, teve destaque ao verificar um crescimento superior a outros ramos da indústria da construção e outros setores da economia brasileira. As empreiteiras brasileiras cresceram de maneira sem precedentes no período, beneficiadas pelo projeto da ditadura de modernização capitalista acelerada do país. Assim, essas empresas, que começavam a assumir uma feição nacional às vésperas do golpe assumiram no final da ditadura o patamar de conglomerados econômicos com tentáculos em diversos setores da economia para além da construção civil - organizados na forma de oligopólio no mercado nacional de obras públicas e dotados de atividades internacionais, visto que elas começaram a tocar obras fora do Brasil desde os finais da década de 1960 .

A ditadura proporcionou um ambiente ideal para as atividades e para os lucros dos empreiteiros brasileiros. Ao longo do regime, a arrecadação de recursos para o fundo público foi ampliada significativamente através das reformas do Paeg (Plano de Ação Econômica do Governo, do período Castello - 1964/1967) e da criação de poupanças compulsórias (FGTS, PIS, Pasep etc.) e o orçamento foi direcionado para gastos em investimentos, na forma de obras públicas de engenharia, inclusive em detrimento das inversões em Saúde e Educação, cujas fatias no orçamento público foram decaindo paulatinamente ao longo do regime. Os gastos públicos centralizados no governo federal permitiram a realização de grandes projetos de infra-estrutura, demandados às maiores empresas do setor, que cresceram mais que as outras, caracterizando um processo acentuado de concentração na construção pesada no período. As políticas favoráveis às empreiteiras foram materializadas também na forma de financiamentos subsidiados, isenções fiscais direcionadas e a reserva do mercado doméstico às empreiteiras nacionais, livrando-as da competição com as construtoras estrangeiras e fortalecendo suas práticas cartelistas. As políticas destinadas aos trabalhadores agiram em favor dos empresários do setor, ao garantir a compressão salarial, cerceamento das formas de organização e atuação coletiva dos trabalhadores e também uma certa displicência em relação aos mecanismos de segurança dos operários nos canteiros de obras, o que fez elevar crescentemente os índices de acidentes de trabalho, estatística que teve o Brasil como recordista no período, sendo o setor da construção civil o líder nacional nas cifras de acidentes e mortes de trabalhadores. Por fim, o amordaçamento dos mecanismos de 
fiscalização - como partidos, parlamento, oposição, movimentos sociais e imprensa proporcionou um ambiente no qual os empreiteiros puderam dispor de acesso direto ao aparelho de Estado, usando artifícios que permitiram a maximização de seus lucros, nem sempre com o uso dos melhores padrões de qualidade nas obras e excelência em uso adequado e regular dos recursos públicos (CAMPOS, 2014).

Os empreiteiros não encontraram esse cenário favorável na ditadura por acidente. De fato, além de suas atividades se combinarem de forma virtuosa com o projeto da ditadura de disponibilizar de maneira célere a base física para a expansão do processo de acumulação de capital no Brasil, esses empresários desempenharam uma participação bastante ativa no golpe civil-militar de 1964. Esse engajamento pode ser verificado ao menos em parte em função do comprometimento de alguns importantes empresários da construção brasileiros nas ações do Instituto de Pesquisas e Estudos Sociais (Ipes). Para entender melhor o comprometimento dos empreiteiros no Ipes e na derrubada do governo João Goulart, é necessário conhecer previamente as formas organizativas desses empresários no âmbito da sociedade civil. ${ }^{1}$

\section{Os empreiteiros e o Sinicon}

Antes do golpe de Estado de 1964, um período muito importante para o avanço das atividades dos empresários da construção pesada - e, inclusive, para o desenvolvimento das suas formas associativas - foi o que correspondeu ao governo Juscelino Kubitschek (19561961). Nesse quinquênio, com as obras previstas no Plano de Metas, expressas sob a forma principal de empreendimentos nas áreas de transportes (sobretudo obras rodoviárias) e energia (em especial na forma de barragens e usinas hidrelétricas), e com a construção da nova capital federal, os empreiteiros viram as demandas às suas atividades serem elevadas de forma inédita até então na trajetória do desenvolvimento do capitalismo no Brasil.

Além de possibilitar que as empresas do setor tivessem seu porte elevado, com a ampliação do faturamento e do seu pessoal, as obras do período JK foram responsáveis por uma mudança qualitativa no setor, que passou de uma condição dominantemente regional para possuir um caráter verdadeiramente nacional. Antes, as empresas de construção pesada, mesmo as maiores delas, tinham uma marca genuinamente local ou estadual, sendo reconhecidas basicamente como paulistas, mineiras, cariocas etc. Com os empreendimentos do Plano de Metas, pode-se verificar finalmente o advento de um mercado nacional de obras públicas, com a contratação pelo governo federal de empresas de diferentes origens

\footnotetext{
${ }^{1}$ Nossa abordagem da sociedade civil e dos aparelhos privados de hegemonia se postula nas reflexões de Antonio Gramsci (2001) e Sonia Mendonça (1998; 2007).
} 
regionais para a realização de obras, em especial as rodoviárias, em diferentes localidades do território nacional, e para erguer a cidade de Brasília, no planalto central.

Não à toa datam desse período as primeiras associações nacionais de empresários do setor, como a Câmara Brasileira da Indústria da Construção (Cbic) e o Sindicato Nacional da Construção Pesada (Sinicon). Antes, as formas organizativas desses empresários se restringiam a uma dimensão regional ou local, expressa em iniciativas como a Associação Paulista dos Empreiteiros de Obras Públicas (Apeop, de 1947). Era comum também que esses empresários se fizessem representar em entidades como o carioca Clube de Engenharia (formado em 1880) e o paulista Instituto de Engenharia (datado de 1917).

Dentre essas novas organizações dos empreiteiros no âmbito da sociedade civil, o Sinicon constitui o mais importante dos aparelhos privados de hegemonia dos empresários brasileiros da construção pesada. Ao contrário da Cbic, que se propunha a ser uma ampla câmara que reunia interesses de todos os ramos da construção civil, incluindo empreiteiros de obras públicas e construtores imobiliários - que, não raro, entravam em choque na organização -, o Sinicon já nasceu como uma associação específica dos empreiteiros de obras públicas, atuando em defesa e benefício dessa fração particular do empresariado da engenharia. Dando aparência de um sindicato inativo e silencioso, o Sinicon dispunha de forte atuação e poder junto ao aparelho de Estado, além de canais próprios de comunicação e difusão de seus interesses e ideias para a sociedade. Mesmo com a diversidade de empresários em seu interior, o sindicato apresentou uma marcante capacidade de adaptação a diferentes contextos, ligando-se ao Ipes-Ibad (Instituto de Pesquisas e Estudos Sociais/Instituto Brasileiro de Ação Democrática) no período 1961-1964, ao mesmo tempo em que seus filiados obtinham obras e financiavam o governo Goulart; aproximou-se ostensivamente da figura de Mário Andreazza durante o "milagre"; e, na época da abertura, mudou parte do seu foco, detendo-se nos contatos com o Legislativo, em especial durante a Constituinte. Essa capacidade de adaptação ficou evidente nas mudanças nas diretorias e presidências no sindicato, que, não raro, coincidiam com as mudanças do governo e dos ministros dos Transportes (CAMPOS, 2014).

Como indicado, o contexto da fundação do Sinicon é o das obras do Plano de Metas do período Kubitschek, sendo que o advento do sindicato é consequência direta das políticas de investimentos em obras públicas adotadas a partir de 1956. Apesar da aproximação entre empreiteiros de diferentes regiões do país proporcionadas pelas obras da nova capital federal, o que unia os empresários do Sinicon não foi exatamente aquele projeto específico, mas o fato de todos eles serem construtores rodoviários que prestavam serviço para o Departamento Nacional de Estradas de Rodagem (DNER).

A reunião formal para criação do Sinicon ocorreu no dia 10 de março de 1959, no escritório da construtora Sotege, pertencente a João Alfredo de Castilho, na rua Debret, no Rio, onde até os dias atuais se encontra a sede do sindicato. Às 18 horas daquele dia, 
estavam reunidos no referido escritório diretores de 41 empresas, sendo eles "os sócios e representantes das firmas abaixo assinadas e que têm como objetivo comercial e industrial a Empreitada de estradas, pontes, portos, aeroportos, barragens e pavimentação, com a finalidade exclusiva de criar uma Associação" (SINICON, 1959, p. 1). Castilho, que viria a ser o primeiro presidente da entidade, dirigiu os trabalhos de fundação, e um esboço do seu estatuto foi apresentado na ocasião. Assim como ocorreu com outros sindicatos de empreiteiros fundados posteriormente, a formação do Sinicon foi precedida da criação de uma associação, no caso a Associação Profissional dos Empreiteiros de Estradas, Pontes, Portos, Aeroportos, Barragens e Pavimentação (SINICON, 1959). Como se verifica no título da entidade, as rodovias detinham uma condição preponderante, não havendo, por exemplo, referência às obras ferroviárias ou similares.

Os primeiros artigos do estatuto indicavam as funções da associação que estava sendo criada e seus objetivos, sendo ela

constituída para fins de estudo, coordenação, proteção e representação legal de seus associados na base territorial nacional e com o intuito de colaboração com os poderes públicos e demais associações profissionais no sentido de solidariedade das classes e da sua subordinação aos interesses nacionais $[\ldots]$

Artigo 2ำ - São prerrogativas da Associação: a) representar perante as autoridades administrativas e judiciárias, os interesses dos associados, relativamente à atividade profissional. b) colaborar com o Estado, como órgão técnico consultivo, no estudo e solução dos problemas que se relacionem com a profissão.

Artigo 3o - São deveres da Associação: a) colaborar com os poderes públicos, e com as organizações sindicais no desenvolvimento da solidariedade das profissões. (SINICON, 1959, p. 1)

Como se vê, desde sua formação e na primeira ordem das suas prioridades estava a função de atuar junto ao aparelho de Estado. Outros deveres seriam manter serviços de assistência para as firmas e buscar a conciliação de dissídios entre associados. $O$ órgão dizia almejar também objetivos mais amplos, como a "consolidação e expansão da infraestrutura do País" (SINICON, 1959, p. 1), o que é indicativo do caráter ideológico e hegemônico de suas proposições e projetos.

A legislação trabalhista de então obrigava que a criação de um sindicato fosse precedida por uma associação profissional. O Sindicato Nacional da Indústria da Construção de Estradas, Pontes, Portos, Aeroportos, Barragens e Pavimentação foi reconhecido em 15 de setembro de 1960, um ano e meio após a fundação da associação, porém ainda no governo JK. No entanto, parece claro que desde a reunião inicial, já se previa a 
transformação da sociedade em uma entidade sindical, conforme se verifica no seu artigo 6o: "Na sede da Associação encontrar-se-á, segundo o modelo aprovado pelo Ministério do Trabalho, Indústria e Comércio, um livro de registro de associados, e do qual deverão constar as especificações exigidas no artigo anterior" (SINICON, 1959, p. 2). Assim, desde o princípio, os empreiteiros associados pretendiam seguir as normas do Ministério do Trabalho, com o objetivo de dotar a nova entidade de representante legal e trabalhista das empresas. O nome da instituição foi mantido de 1960 a 1998, quando foi modificado para Sindicato Nacional da Construção Pesada, mantendo a sigla Sinicon (SINICON, 2004, p. 5).

Deve-se pontuar que o período final do governo JK é marcado por uma intensificação das mobilizações de organizações de trabalhadores e de seus movimentos grevistas, inclusive na construção civil. Dessa forma, a fundação do Sinicon obedecia também a um objetivo de unir os empresários do setor diante da crescente atuação do operariado da construção (SOUSA, 1978).

Ficou decidido também no ato de fundação que os mandatos das diretorias e dos conselhos fiscais seriam de dois anos, devendo ser preenchidos por brasileiros, e o presidente da instituição deveria ser um brasileiro nato. Ao contrário da Abeop (Associação Brasileira dos Empreiteiros de Obras Públicas, entidade fundada em 1953 no Rio de Janeiro, ligada ao Clube de Engenharia, que acabou não se firmando como forma de organização dos empreiteiros), o Sinicon não teve empresas estrangeiras em sua reunião de fundação e não parece ter tido posteriormente. Havia restrições também que não eram de cunho nacional: "Não se podem candidatar aos cargos administrativos ou de representação profissional: a) os que professarem ideologias incompatíveis com as instituições e os interesses da Nação" (SINICON, 1959, p. 3). A polarização política vivida no Brasil e no mundo de então atravessava a nova instituição, e o caráter abertamente direitista e anticomunista de alguns de seus associados ficava expresso no texto inaugural da entidade, o que a diferenciava da Abeop. Já ao presidente competia "representar a Associação, perante a Administração Pública" (SINICON, 1959, p. 4), e no final da reunião de fundação foi eleita em chapa única a sua primeira diretoria, vigente por apenas um ano e presidida por João Alfredo Castilho.

$\mathrm{Na}$ ata, é possível perceber um claro desequilíbrio regional entre os fundadores da entidade. Figuram na lista ao menos representantes de 41 construtoras, sendo 40 identificadas. Pode-se verificar a presença maciça de empreiteiras rodoviárias e também das maiores construtoras do país de então, como Rabello, Camargo Corrêa, Metropolitana, Andrade Gutierrez, CBPO e Sotege. Vê-se uma maioria de empresas cariocas ou do estado do Rio, 27 das 40 identificadas. Isso se deve aparentemente ao fato de a sede da entidade ser na cidade e à forte ligação que as empreiteiras do Rio tinham com o DNER, em especial no governo JK, quando o MVOP (Ministério de Viação e Obras Públicas) e a autarquia foram controlados pelo PSD fluminense (BENEVIDES, 1976). Muitas dessas construtoras foram à falência posteriormente e deram lugar a empreiteiras paulistas, mineiras e nordestinas como as principais no mercado nacional de obras públicas nos anos 60 e 70 . Essa relação do Sinicon com o Rio e suas empresas recuou com o passar do tempo, mas não se anulou 
plenamente, já que, mesmo após a transferência da capital, o DNER e outras instituições estatais permaneceram com suas sedes na cidade.

Apenas uma nordestina, a Comasa, parece ter participado da reunião de fundação da associação, porém, já em 1961, Odebrecht e Queiroz Galvão se filiaram ao sindicato. Apesar da presença considerável de firmas mineiras e paulistas, cinco em cada caso, uma construtora do porte da Mendes Júnior só se filiou em agosto de 1964 (SINICON, 2010). Fora essas ausências, todos os grandes empresários da construção pesada do país naquele momento estavam presentes na reunião de fundação da entidade. O número de firmas filiadas, que começou com aproximadamente 40, era de 185 em 1984 (SINICON, 1984), e no início do século XXI chegava a 450, apesar de serem apenas 104 associadas mantenedoras (SINICON, 2007).

O Sinicon reuniu empresas que atuavam em especial para agências do aparelho de Estado nacional, como o DNER, o DNOS (Departamento Nacional de Obras de Saneamento), o BNH (Banco Nacional de Habitação), a Eletrobrás etc. O foco principal, no entanto, sempre foi a área de transportes e o Ministério de Viação e Obras Públicas - após 1967, Ministério dos Transportes - era o principal alvo das investidas e movimentos do sindicato. Era comum que o Sinicon acompanhasse o orçamento dessa pasta e de suas autarquias, repassando informações aos seus associados. Da mesma forma, a entidade elaborava projetos para o setor, como se pode depreender do título do editorial do Informe Sinicon de junho de 1984: "Sinicon enviou ao Ministério dos Transportes proposta de obras" (SINICON, 1984B, p. 1). Eram comuns as reuniões com os ministros e altos funcionários do ministério, havendo fóruns conjuntos e encontros do Sinicon com os membros daquela pasta governamental.

Essa atuação junto aos órgãos da sociedade política ia contra os princípios da concorrência e imparcialidade, supostamente praticados nas licitações. Assim, uma das funções do sindicato era receber os editais dos órgãos contratantes do governo e realizar, dentro do Sinicon, a divisão da obra entre os seus integrantes, acertando lances de preços nas concorrências. Enfim, o Sinicon era o ambiente de implementação de práticas cartelistas, o que ficou evidente através do primeiro informe interno do sindicato, em que uma matéria tinha o seguinte título: "O Sinicon quer dividir obras rodoviárias" (SINICON, 1984A, p. 1).

Os primeiros presidentes do sindicato são arrolados no quadro a seguir:

Quadro 1 - Primeiros presidentes do Sinicon:

\begin{tabular}{|l|c|c|}
\hline Presidente: & Empresa: & Período da presidência: \\
\hline João Alfredo Castilho & Sotege & Março/1959 a Novembro/1960 \\
\hline
\end{tabular}




\begin{tabular}{|l|c|r|}
\hline Haroldo Cecil Poland & Metropolitana (CMC) & Novembro/1960 a Dezembro/1962 \\
\hline Marco Paulo Rabello & Rabello & Dezembro/1962 a Dezembro/1964 \\
\hline Djalma Murta & Brasil & Dezembro/1964 a Junho/1974 \\
\hline
\end{tabular}

Fonte: SINICON (2004).

Uma das marcas que se percebe na relação dos primeiros presidentes da entidade é a coincidência entre a mudança da gestão e dos diferentes governos no país. Essas modificações foram intencionais: como veremos adiante, Rabello era um empreiteiro mineiro próximo de JK e, apesar de ter financiado o Ipes, não era bem visto pelo grupo que tomou o poder em 1964 e, por isso, não foi reeleito presidente do Sinicon, dando lugar a um empresário mais afinado com os civis e militares golpistas. É possível afirmar, portanto, que a figura do presidente da entidade parecia ser escolhida com o objetivo de assegurar consonância com o governo instituído e com as agências com os quais o sindicato atuava. Já nas diretorias da instituição, havia uma diversidade maior de nomes, sendo perceptível a presença de empresários não necessariamente afinados com a gestão federal. Assim, após sair da presidência, Marco Paulo Rabello assumiu funções menores na diretoria do sindicato, participando cinco vezes seguidas do Conselho Fiscal, posto geralmente ocupado pelos expresidentes da entidade (SINICON, 2004).

A primeira diretoria do Sinicon, ainda sob a condição de associação, foi exercida por um empresário estreitamente ligado ao governo Kubitschek. Existem relatos de que João Alfredo Castilho ofereceu de presente uma casa no Paraguai a JK, após ter realizado diversas obras federais no seu governo (PRADO, 1997). Haroldo Poland, próximo de Lacerda e da UDN, foi escolhido presidente do Sinicon no período Jânio Quadros, e Marco Paulo Rabello, ligado a JK e aos políticos do PSD e PTB, liderou a entidade no governo Goulart. Sob o governo Jango, o Sinicon teve dois presidentes que financiaram o Ipes e o sindicato integrou a estrutura da sociedade civil anti-Jango, liderada pelo complexo Ipes-Ibad. Apesar disso, os empreiteiros tiveram muitas obras no período, contratadas pelo DNER e outras autarquias federais.

O golpe de 1964 gerou turbulências no Sinicon, já que o presidente da instituição era publicamente próximo de JK, logo convertido em inimigo do novo regime. Para justificar a cassação dos direitos políticos do ex-presidente, foram indicadas diretamente as relações ditas ilegais que este mantinha com Marco Paulo Rabello. Essa situação constrangedora atingiu órgãos públicos ligados ao sindicato. Em 31 de março de 1964, a sede do DNER, na avenida Presidente Vargas, foi invadida por militares, sendo seu diretor geral e vários funcionários exonerados imediatamente. Um deles, Igesipo Miranda, encaminhou-se ao Sinicon, onde foi abrigado e empregado. Além disso, o diretor geral do DNER, Roberto 
Lassance, foi trabalhar em uma empresa filiada ao sindicato, a CR Almeida ${ }^{2}$. Esses exemplos dão o tom da estreita relação Sinicon-DNER e também da relação complexa e contraditória existente entre o Sinicon e o golpe de 1964.

A "Revolução" ${ }^{3}$ levou à substituição de Rabello da direção da entidade, assumindo em seu lugar o empreiteiro Djalma Murta, ex-acionista da Mantiqueira e diretor da Brasil Construtora S.A., empresa carioca de médio porte. Murta foi o mais longevo presidente do Sinicon até a gestão de Luiz Fernando Santos Reis (1995-2013) e sua presidência corresponde à primeira metade do regime ditatorial. Em sua gestão, o Sinicon pouco se expôs publicamente, mas manteve forte atividade junto ao governo, estabelecendo uma sólida parceria com o ministro Mário Andreazza após 1967. O conjunto de empreiteiros, organizado no Sinicon, aglomerou-se em torno do primeiro ministro dos Transportes, e o sindicato funcionou nesse momento como um autêntico partido, com seus próprios meios de difusão de idéias para toda a sociedade, no caso, os jornais antes controlados por Niomar Sodré Bittencourt (Correio da Manhã) e Samuel Wainer (Última Hora). Murta esteve na liderança do Sinicon durante quatro diretorias, apresentando-se sempre como líder de uma chapa única, sendo as duas últimas de três anos, como passaria a valer a partir de então, segundo a reforma do estatuto. Essas diretorias pouco se diferenciaram, com os mesmos nomes assumindo diferentes posições nos quadros da entidade (SINICON, 2004).

Apesar do caráter social bastante limitado do Sinicon, organização restrita aos empresários do setor da construção pesada, a entidade não ficou isolada de outras representações da sociedade civil. Pelo contrário, o que se nota no início dos anos 1960 é que a organização dos empreiteiros integrou com outras formas de associativismo burguês, inclusive com características e objetivos mais específicos e concretos, como é o caso do Ipes.

\section{Os empreiteiros e o Ipes}

O Instituto de Pesquisas e Estudos Sociais, organismo empresarial-militar criado em 1961 que atuou para desestabilizar e derrubar o governo João Goulart, tinha uma acentuada presença de construtores urbanos e empreiteiros. Não só o Ipes ajudou a organizar o empresariado brasileiro em torno de um projeto político, mas o próprio instituto estava assentado em organizações empresariais e militares anteriormente existentes. Dreifuss destaca a íntima relação do Ipes com a ESG (Escola Superior de Guerra) e a Adesg (Associação de Diplomados da ESG), pelo lado militar, e com Fiesp (Federação das Indústrias

\footnotetext{
${ }^{2}$ Entrevista informal realizada com o engenheiro Darcylo de Carvalho Laborne e Valle, em 14 de maio de 2010, na visita realizada ao Sinicon.

${ }^{3}$ Termo usado pelo diretor do Sinicon, Darcylo de Carvalho Laborne e Valle, em 14 de maio de 2010.
} 
do Estado de São Paulo), ACRJ (Associação Comercial do Rio de Janeiro) e outras entidades empresariais, em sua face civil. Haroldo Cecil Poland era um dos principais membros do Ipes, sendo também, entre 1960 e 1962, presidente do Sinicon, entidade que prestou suporte ao instituto e teve vários filiados que colaboraram com o órgão. No quadro abaixo, com dados retirados do estudo de Dreifuss, é possível verificar as empresas de engenharia e construção que contribuíram com o Ipes:

Quadro 2 - Empresas de engenharia e construção que contribuíram com o Ipes:

\begin{tabular}{|c|c|}
\hline Empresa: & Empresários e grupos envolvidos: \\
\hline $\begin{array}{l}\text { Ceibrasil - Cia. de Engenharia e Indústria - } \\
\text { Worthington Corp. NJ, Fila Junqueira Botelho }\end{array}$ & $\begin{array}{l}\text { Nanto Junqueira Botelho; Eduardo Baker } \\
\text { Andrade Botelho }\end{array}$ \\
\hline Construtora Rabello S.A. & Marco Paulo Rabello; Milton José Mitidieri \\
\hline $\begin{array}{l}\text { Cimento Portland Barroso - Paulo Mário } \\
\text { Freire }\end{array}$ & $\begin{array}{l}\text { Grupo Severino Pereira da Silva; Grupo } \\
\text { Holderbank Financière Glaris }\end{array}$ \\
\hline $\begin{array}{l}\text { EEE - Empreendimentos e } \quad \text { Estudos } \\
\text { Econômicos }\end{array}$ & Gilbert Huber Jr.; Eurico Castanheira \\
\hline Empreendimentos Villela S/A Adm. e Part. & Maurício Libâneo Villela \\
\hline Engefusa Engenharia e Fundações S/A & $\begin{array}{l}\text { José Soares Sarmento Barata; Raymundo } \\
\text { José D'Araújo Costa; Carlos da Silva; Lauro } \\
\text { Rios Rodrigues }\end{array}$ \\
\hline Companhia Metropolitana de Construções & Haroldo Cecil Polland \\
\hline Metminas S/A Engenheiro Consultores & Amynthias Jaques de Moraes \\
\hline Montreal Engenharia S/A & $\begin{array}{l}\text { Tomaz Pompeu Borges Magalhães; } \\
\text { Brigadeiro Eduardo Gomes; A. Azevedo } \\
\text { Silveira; Coronel Haroldo Corrêa de Mattos }\end{array}$ \\
\hline R. J. Oakim Engenharia S/A & Roberto Jorge Oakim \\
\hline Parquet Paulista S/A & $\begin{array}{l}\text { Manuel Garcia Cruz; Oscar Figueiredo; Luiz } \\
\text { Lima da Costa; Luiz Manuel da Cruz; Gilberto } \\
\text { Garcia Cruz }\end{array}$ \\
\hline Servience Cia. de Serviços de Engenharia & Amynthias Jaques de Moraes \\
\hline
\end{tabular}




\begin{tabular}{|c|c|}
\hline $\begin{array}{l}\text { Sociedade Civil de Controle de Concreto e } \\
\text { Ensaios de Materiais - Concremat }\end{array}$ & Maurício Ribeiro Viegas \\
\hline Cia. de Cimentos Vale Paraíba & $\begin{array}{l}\text { João M. S. Castro; Jean Koranyi; Manoel } \\
\text { Azevedo Leão; T. Marcondes Ferreira; Paulo } \\
\text { Fontainha Geyer }\end{array}$ \\
\hline $\begin{array}{l}\text { Cia. de Cimentos Portland Paraíso - Cia. } \\
\text { Nacional de Estamparia }\end{array}$ & $\begin{array}{l}\text { Severino Pereira da Silva; Carlos A. M. } \\
\text { Pereira da Silva; Paulo Mário Freire }\end{array}$ \\
\hline $\begin{array}{l}\text { Escritório de Engenharia Antônio Alves de } \\
\text { Noronha }\end{array}$ & \\
\hline $\begin{array}{l}\text { Gomes de Almeida Fernandes Engenharia e } \\
\text { Construções Ltda. }\end{array}$ & \\
\hline Urbanizadora de Parques e Jardins & \\
\hline $\begin{array}{l}\text { Campo Cia. Auxiliar de Melhoramentos, } \\
\text { Produção e Obras }\end{array}$ & \\
\hline Geovia Comércio e Engenharia S. A. & \\
\hline Construtora Lemos S. A. & \\
\hline Sisal Imobiliária Sto. Afonso & \\
\hline Auxiliadora Predial S.A. & \\
\hline Imobiliária Zirtaeb Ltda. & \\
\hline Doradim Administação e Participações & \\
\hline José Carlos Leone e Associados Consultores & \\
\hline Leone Consultora e Planejamento Ltda. & \\
\hline
\end{tabular}

Fonte: DREIFUSS, 1981, p. 636 [grifo nosso].

No quadro acima, pode-se ver várias empresas de consultoria e setores próximos ao da construção civil, como produção de cimentos, imobiliárias etc. Algumas empresas de construção que doaram recursos ao Ipes foram a Rabello, a Montreal, a Kosmos, a Gomes de Almeida Fernandes (Gafisa), a Metropolitana, a Servienge e a Sisal. Alguns controladores dessas empresas tinham relações próximas com outros agentes responsáveis pelo golpe e da 
ditadura. Assim, Carlos Moacyr Gomes de Almeida, da Gafisa, era próximo de Sandra Cavalcanti e assumiu funções pública após o golpe de Estado. O brigadeiro Eduardo Gomes, um dos acionistas da Montreal no período, foi um dos militares que participou da articulação do golpe. Por fim, a Sisal - que atuava tanto na incorporação imobiliária como na construção civil - era controlada por Jadir Gomes da Silva, próximo de militares, como o general Artur da Costa e Silva, seu amigo pessoal, com quem jogava cartas periodicamente (GASPARI, 2002)

Assim, os empreiteiros inscreviam suas formas de organização na sociedade civil em apoio às causas políticas e estratégicas do Ipes, fortalecendo o movimento de desestabilização do governo Jango. Ou melhor, o Sinicon integrou a rede de associações empresariais que serviram de base à constituição e ação do Ipes, sendo uma das entidades burguesas que contribuiu para a faceta civil do golpe de Estado de 1964.

O Ipes perdurou até 1971, sendo então extinto. Em 1978, tentaram recuperá-lo sem sucesso e, nos anos 80, o banqueiro e ex-ipesiano Jorge Oscar de Mello Flôres explicou que não conseguia recriar a entidade, porque naquele momento o empresariado estava

fragmentado por interesses setoriais e regionais, que procuram afirmar-se uns contra os outros. Não há coesão ideológica ou articulação política, embora os tempos tornem evidente a necessidade de organizar pelo menos a cúpula do setor privado, dando-lhe efetivo poder de pressionar e influenciar decisões. (DREIFUSS, 1986, p. 258)

Dentro da estrutura do Ipes, funcionava a unidade de 'Reforma Habitacional (Estudo econômico e legal sobre causas populares)', na qual atuava Sandra Cavalcanti e Guilherme Borghoff, ambos secretários do governo Lacerda no estado da Guanabara e empresários, sendo Cavalcanti ligada à construtora Hosken, que atuava na construção imobiliária no Rio. Esses nomes passaram a figurar na administração pública após o golpe, sendo que Sandra Cavalcanti foi para a chefia do $\mathrm{BNH}$, projeto concebido pelo seu grupo de estudo no Ipes. $\mathrm{O}$ empresário da construção civil do Rio, Carlos Moacyr Gomes de Almeida, do Ipes e ligado a Sandra Cavalcanti, ficou com o projeto piloto do BNH, o Programa de Cooperativa Habitacional do estado da Guanabara (DREIFUSS, 1981).

Dentre esses empreiteiros ipesianos, cabe abordar um pouco mais detidamente dois deles, Marco Paulo Rabello e Haroldo Poland, já que eram empresários muito importantes no ramo da construção pesada e, ao mesmo tempo, detinham um papel político bastante relevante, apesar de terem tomado rumos completamente distintos após o golpe de 1964 .

Marco Paulo Rabello, originário de Diamantina, em Minas Gerais, formou-se em Engenharia em 1941 e começou trabalhando na empresa de construção do tio, Ajax Rabello, até formar em Belo Horizonte, em 1944, a sua própria construtora, a Rabello. A empresa 
construiu o complexo da Pampulha para a prefeitura de Belo Horizonte na gestão Kubitschek, iniciando ali uma sólida relação com os projetos de Oscar Niemeyer. A Rabello seguiu Juscelino no governo estadual, realizando obras rodoviárias, e, na gestão JK na União, ficou incumbida da construção de todo o eixo monumental de Brasília, incluindo os palácios do Planalto e Alvorada. A empreiteira realizou também trechos de rodovias como a Régis Bittencourt, Dutra e Castello Branco.

Segundo Marco Paulo: "O Juscelino me ajudou muito, sim, éramos amigos." (CARVALHO, 2001, p. 416). O empresário teve ligações também na imprensa, com Samuel Wainer e David Nasser, ajudando na manutenção do Última Hora (WAINER, 1988). Foi casado com a negociante de arte, Valéria Braga, que teve um caso e aparente filho ilegítimo com Joaquim Monteiro de Carvalho, o Baby, do grupo Monteiro Aranha (VEJA, 2000). As ligações de Rabello com JK e seu grupo político não foram proveitosas na conjuntura política a partir da década de 1960:

Você quer ver uma empresa que foi para o brejo porque não teve boas relações políticas? Foi a Rabello. A Rabello era ligadíssima ao Juscelino; construiu Brasília, construiu a São Paulo-Curitiba, construiu a Belo Horizonte-São Paulo, etc... Era amiga de Juscelino. Sua queda começa com Jânio Quadros, se completando com a revolução de 64 . [...] Nessa nossa área, o esquema político funciona. Então o Marco Paulo Rabello (presidente da Rabello) tinha bom relacionamento com Juscelino. Nesta época, houve um 'boom' de obras em todos os setores e o Marco fez uma senhora empresa. Ele era um senhor empresário. Posteriormente, em decorrência desse fato, com a revolução de 64, o Marco ficou de certa maneira marginalizado em termos políticos. Isto devido a suas vinculações pessoais com o Juscelino. Então, ele foi muito podado, muito cortado. (FERRAZ, 1981, p. 95-6)

Esse depoimento foi obtido pelo economista Galeno Tinoco Ferraz Filho em entrevista anônima realizada com um empreiteiro. A Rabello perdeu seguidamente concorrências após o golpe e foi usada como motivo para a cassação em 1964 dos direitos políticos de Juscelino Kubitschek, que era acusado de beneficiar empreiteiras com artifícios ilícitos, em especial a Rabello.

Com essas dificuldades, Marco Paulo, que havia financiado o Ipes e presidido o Sinicon, usou intermediários para tentar desobstruir as dificuldades que acometiam sua empresa. Acionou José Maria Alckmin, David Nasser e seus contatos na imprensa, chegando a empregar um coronel na empresa. Enviou uma carta ao ditador Castello Branco tentando atenuar as perdas da empresa no período, sem obter êxito (CARVALHO, 2001). O período do ministro dos Transportes Mário Andreazza (1967-1974) permitiu uma sobrevida à 
empreiteira, evidente em contratos como a UHE de Passo Fundo, trechos da Transamazônica, Rio-Santos, Niterói-Manilha, Minhocão de São Paulo, Ferrovia do Aço e parte no consórcio que construiu a ponte Rio-Niterói. Porém, ao longo da década de 1970, a empresa perdeu posições dentre as maiores do país, passando de 6ㅇ lugar em 1971, para 7o em 1972, 12ㅇem 1973, 17ㅇe em 1974, 21ㅇe em 1976 e sumindo da lista desde então, quando parece ter pedido concordata (O EMPREITEIRO, 1971-1976).

Diante das dificuldades no mercado doméstico, a empreiteira buscou oportunidades no exterior e obteve contrato para construção de universidade na Argélia através de uma indicação indireta do arquiteto da obra, Oscar Niemeyer. Sem contar com ajuda governamental, como era comum com as empreiteiras que atuavam no exterior, a Rabello realizou outras obras no país, mas devido a problemas políticos locais, aquele mercado também se fechou para a empresa em fins dos anos 70 e a decadência da Rabello a partir de então tomou uma trajetória irreversível (FERRAZ, 1981).

Já o também empreiteiro Haroldo Cecil Poland teve trajetória distinta de Marco Paulo Rabello, ao ter desenvolvido uma movimentação bastante ativa no golpe de Estado de 1964 e não ter sofrido retaliação no início da ditadura. Poland desempenhou a função de líder de boa parcela dessa fração social ao assumir a primeira presidência do Sinicon e ter sido o principal empresário do setor envolvido com o golpe de 1964.

Presidente da Companhia Metropolitana de Construções na década de 1960, Poland era também sócio do Banco Português do Brasil e acionista de outras companhias (CARVALHO, 2001). Além disso, presidiu o sinicon e foi o representante brasileiro nos anos 60 no Conselho Interamericano de Comércio e Produção (Cicyp), importante organização burguesa internacional no período estudada por Dreifuss (1986) em A Internacional Capitalista. Foi a partir dessas duas posições que ele se postulou como líder dos empreiteiros, participando do esforço empresarial-militar do Ipes para desestabilizar o governo Jango e elaborando projetos para um novo governo. Poland teve intensa atuação no Ipes, aliciando inclusive outros empreiteiros a financiá-lo, como Marco Paulo Rabello, que afirmou: "O Poland me convenceu a contribuir com o IPES" (CARVALHO, 2001, p. 417).

No instituto, Poland atuou no estudo sobre "Reforma do Legislativo e da Administração Pública". É interessante notar que a unidade à qual Poland estava ligado no Ipes foi responsável pelo projeto básico que deu origem à reforma administrativa do Estado brasileiro no governo Castello, que conferiu autonomia e agilidade para autarquias estatais contratarem empresas privadas, inclusive empreiteiras (BORTONE, 2013). Além disso, Poland arrecadou recursos para ajudar os Círculos Operários, movimento de trabalhadores oposto aos sindicatos combativos e orientado pelo padre Velloso, educador jesuíta e engenheiro civil que foi o primeiro reitor da PUC-Rio e um dos criadores da universidade (DREIFUSS, 1981). 
No interior do Ipes, Poland era muito ligado ao coronel Golbery do Couto e Silva, sendo considerado o ipesiano civil mais próximo do militar. Elio Gaspari, de posse do arquivo de Golbery, afirma que, quando este estava estruturando o SNI (Serviço Nacional de Informações), mantinha contato telefônico diário com oito pessoas, seis militares e dois civis, dentre os quais Haroldo Poland (CARVALHO, 2001). Quando Golbery planejava governar a Guanabara, cogitou Poland para uma secretaria estadual (GASPARI, 2003). No dia do golpe de 1964, Poland foi armado para a casa de David Nasser, na Tijuca, e, segundo o jornalista Luiz Maklouf de Carvalho, ele foi um "empresário de peso na grande conspiração civil-militar que derrubou Jango" (CARVALHO, 2001, p. 417). Muito ativo no primeiro governo da ditadura, Poland foi cogitado para a presidência do BNH, quando Sandra Cavalcanti deixou o cargo, mas foi preterido em favor de Mário Trindade (DREIFUSS, 1981).

$\mathrm{Na}$ década de 1970, o controle da Metropolitana passou para Maurício Nunes Alencar e Frederico Gomes da Silva, e os negócios de Poland parecem ter sofrido decadência, como relata seu amigo, o jornalista David Nasser na matéria "O revolucionário esquecido", publicada na revista O Cruzeiro, em 1973. Nessa reportagem, Nasser afirma que as atividades empresariais de Poland não iam bem e reclamava socorro:

Raros homens se arriscaram tanto de maneira tão desprendida quanto Haroldo Cecil Polland. [...] Amigo de Castelo Branco, de Golbery do Couto e Silva, de Costa e Silva, de Cordeiro de Farias, de Magalhães Pinto - Haroldo detestava a evidência. Creio que nunca houve um patriota mais silenciosamente audacioso. (CARVALHO, 2001, p. 520)

A decadência de Poland parece indicar rearranjos na composição política do regime ditatorial na década de 1970. Apesar de seus insucessos empresariais, esses não representavam uma decadência dos empreiteiros, que tinham outros representantes de seus interesses no seio do aparelho de Estado.

\section{Os empreiteiros e o golpe civil de 1964}

Em sua obra, Dreifuss mostra como a quebra da ordem constitucional em 1964 ocorreu como fruto da ação conjugada de segmentos do oficialato militar com empresários brasileiros e estrangeiros, reunidos em organizações como o Ipes, o Ibad e a ESG. Vários foram os representantes da burguesia brasileira presentes no movimento de desestabilização do governo Goulart, de organização da ação do dia primeiro de abril e de articulação do projeto político nacional pós-64. Em especial participavam empresários associados ao capital internacional e que estavam reunidos no Ipes e em organizações relacionadas, ligados a 
oficiais do Exército, como Golbery do Couto e Silva. Como vimos, dentre esses figuravam alguns empreiteiros de obras públicas.

Porém, os empreiteiros em geral não pareciam estar descontentes com as políticas desenvolvidas no final do governo João Goulart. Com o abandono do Plano Trienal e suas metas de austeridade fiscal, amplos recursos públicos foram direcionados para investimentos em obras de infraestrutura, como a construção de rodovias. Vários testemunhos indicam um contentamento do setor com o programa de obras desenvolvido entre 1963 e 1964. Assim, Wilon Quintella, alto dirigente da poderosa Camargo Corrêa, afirmou em seu livro de memórias: "Estávamos vivendo um período de franca atividade, quando chegou o período revolucionário" (QUINTELLA, 2008, p. 245). Além disso, em relação à alteração do nome da rodovia do Oeste, no estado de São Paulo, para estrada Castello Branco, Quintella afirmou em seu livro: “Cá entre nós, o nome original da rodovia era muito mais simpático." (QUINTELLA, 2008, p. 262) Pode-se ponderar que essas afirmações constituem uma leitura realizada a posteriori, mas outros movimentos de empresários da engenharia também convergiam com esses relatos.

Sintomático dessa adesão dos empreiteiros e certo contentamento com o volume de obras no governo João Goulart é o testemunho de Samuel Wainer a respeito dos acontecimentos dos dias que antecederam o golpe de Estado:

Nesse período, os empreiteiros procuraram, com sucesso, consolidar e ampliar seus vínculos com o governo. Passaram, por exemplo a patrocinar comícios - o famoso comício das reformas ocorrido em 13 de março de 64, por exemplo, teve suas despesas pagas por um grupo de empreiteiros. (WAINER, 1988, p. 238)

Assim, alguns empreiteiros de obras públicas detinham uma ação política e vínculos importantes com o governo Goulart.

Havia uma intensa presença de empresários da construção ligados ao Clube de Engenharia dentro das agências estatais no período Jango. Esse grupo foi alijado do poder logo em seguida. Assim, no Clube de Engenharia do Rio de Janeiro, criou-se uma situação embaraçosa com o golpe, já que o presidente do clube, Hélio de Almeida, acumulava a função com o cargo de ministro de Viação e Obras Públicas do governo Goulart. Expresidente da UNE e, segundo Samuel Wainer, político avesso às negociatas de corrupção comuns na pasta (WAINER, 1988), Almeida foi imediatamente demitido do posto no MVOP e pôs seu cargo no clube à disposição, com o objetivo de evitar problemas com o novo governo. Apesar do gesto, o ex-ministro foi mantido no posto até o fim do mandato, em agosto de 1964, quando foi substituído por outro engenheiro na presidência do clube. 0 golpe dividiu o clube, com engenheiros e empresários a favor da derrubada do governo Goulart e outros contra a quebra da ordem institucional no país (HONORATO, 1996). 
A relação tensa do governo do ditador Castello Branco com o Clube de Engenharia não se restringiu ao episódio do golpe de Estado. Ao longo dos três ano de governo, o clube foi o principal organizador do movimento "Em defesa da engenharia brasileira", deflagrado ainda no final do ano de 1964. A mobilização, que envolveu outras associações empresariais do setor da engenharia, criticava a política do governo Castello de contratar empresas de engenharia estrangeiras para elaboração de projetos de obras e empreendimentos que, segundo os líderes da campanha, poderiam ser realizados por empresas nacionais (ROTSTEIN, 1966). Naquele momento, o clube, dividido no golpe, voltava a se agrupar em torno de uma causa comum, dando força a um movimento que levaria à reversão das política para o setor no governo do ditador Artur da Costa e Silva, inclusive levando a medidas relevantes, como a reserva de mercado no setor de obras públicas (CAMPOS, 2014).

\section{Conclusão}

Assim, tentando dar conta da questão de qual foi a relação dos empreiteiros de obras públicas brasileiros com o golpe de 1964, aparentemente a impressão é que parte dessses empresários se engajou e participou ativamente do golpe de Estado de 1964, sendo ativos no Ipes e tendo articulação, inclusive, com os principais conspiradores militares responsáveis pela derrubada do governo Goulart. Uma outra parcela parecia não estar diretamente engajada no movimento que desaguou no golpe, estando mais afastados dos acontecimentos principais que ocorriam no período, havendo inclusive diversos empresários do setor com um bom conjunto de obras e vínculos políticos com o governo Goulart.

Essa digressão empírica não dá conta, no entanto, de uma reflexão mais profunda dessa relação empreiteiros-golpe, que leve em conta alguns postulados teóricos e conceituais. Dessa forma, tentando compreender a ação de classe desses empresários, como eles agiram de forma coletiva, levando em conta suas formas organizativas no âmbito da sociedade civil, é possível afirmar que os empreiteiros de obras públicas brasileiros estiveram, enquanto grupo social, engajados diretamente no golpe de Estado que derrubou a ordem legal e constitucional no país. Isso porque suas formas organizativas e associativas, em particular o Sinicon, não só estiveram envolvidos como integravam ativamente a frente empresarial-militar comprometida com o projeto do Ipes e com a derrubada do governo João Goulart. Nesse sentido, o empresário Haroldo Poland, enquanto ex-presidente do Sinicon e agente extremamente ativo no Ipes, atuou como liderança dessa fração empresarial e representante de seus interesses e projetos junto ao grupo responsável pela ação que pôs fim ao governo Goulart e que também projetou o novo desenho do Estado brasileiro a partir de então. Enfim, a participação dos empreiteiros de obras públicas foi 
extremamente ativa e, até, bastante relevante na articulação civil do golpe de Estado de 1964, estando eles comprometidos com o fim do sistema legal e constitucional brasileiro.

Isso não significa que o processo histórico não carregue uma série de contradições e complexidades. Dessa forma, uma parcela do empresariado do setor acabou virando alvo de retaliação e alijamento do poder no primeiro governo da ditadura. Significativo disso foi o caso da Rabello, que mesmo tendo financiado o Ipes, foi associada a JK e entrou em profunda decadência a partir de então. Da mesma forma, houve perdas para as empreiteiras ligadas ao Clube de Engenharia e ao varguismo, com a paralisação das obras em curso do governo Jango. A demissão de agentes próximos aos empreiteiros no DNER e a contratação de firmas estrangeiras para realização de projetos e obras no país também são sinal de certo rompimento dos novos dirigentes estatais com parcela de empresários do setor. Não à toa, a gestão Castello foi alvo de mobilização dos empresários-engenheiros do Clube de Engenharia e outras associações patronais do setor. Essa situação de tensão só teve reversão em 1967, quando houve um rearranjo das relações de poder no aparelho de Estado e a burguesia industrial nacional ganhou força e presença no bloco de poder, incluindo de maneira mais evidente os empresários da construção pesada.

\section{REFERÊNCIAS BIBLIOGRÁFICAS}

BENEVIDES, Maria Victoria. O Governo Juscelino Kubitschek: desenvolvimento econômico e estabilidade política, 1956-61. Rio de Janeiro: Paz e Terra, 1976.

BORTONE, Elaine de Almeida. A Participação do Instituto de Pesquisas e Estudos Sociais (Ipes) na Reforma Administrativa da Ditadura Civil-Militar. Dissertação de mestrado em Administração. Niterói: UFF, 2013.

CAMPOS, Pedro Henrique Pedreira. Estranhas Catedrais: as empreiteiras brasileiras e a ditadura civil-militar. Niterói: Eduff, 2014.

CARVALHO, Luiz Maklouf. Cobras Criadas: David Nasser e O Cruzeiro. 2a ed. São Paulo: EdSENAC-SP, 2001 [1999].

DREIFUSS, René Armand. 1964: a conquista do Estado. 3a ed. Petrópolis: Vozes, 1981 [1981].

A Internacional Capitalista: estratégias e táticas do empresariado transnacional, 1918-1986. Rio de Janeiro: Espaço e Tempo, 1986.

FERRAZ Filho, Galeno Tinoco. A Transnacionalização da Grande Engenharia Brasileira. Dissertação de mestrado em Economia. Campinas: Unicamp, 1981.

GASPARI, Elio. A Ditadura Derrotada. São Paulo: Companhia das Letras, 2003.

A Ditadura Envergonhada. São Paulo: Companhia das Letras, 2002. 
GRAMSCl, Antonio. Cadernos do Cárcere. 2a ed. Rio de Janeiro: Civilização Brasileira, 2001 [1932-1934]. Vol. 3.

MENDONÇA, Sonia Regina de. "Estado e políticas públicas no Brasil: uma questão conceitual". In: Estado e Educação Rural no Brasil: alguns escritos. Rio de Janeiro: Faperj / Vício de Leitura, 2007. p. 11-20.

MENDONÇA, Sonia Regina de. "Estado e sociedade". In: MATTOS, Marcelo Badaró de (org.). História: pensar \& fazer. Rio de Janeiro: Laboratório de Dimensões da História, 1998. p. 13-32

HONORATO, Cézar Teixeira (org.). O Clube de Engenharia nos Momentos Decisivos da Vida do Brasil. Rio de Janeiro: Venosa, 1996.

PRADO, Lafayette Salviano. Transportes e Corrupção: um desafio à cidadania. Rio de Janeiro: Topbooks, 1997.

QUINTELLA, Wilson. Memórias do Brasil Grande: a história das maiores obras do país e dos homens que as fizeram. São Paulo: Saraiva / Vigília, 2008.

Revista O Empreiteiro. Edições n 57, 73, 80, 91 e 115. São Paulo: Emep, 1971-1976.

Revista Veja. Edição n 1649, de 17 de maio de 2000.

ROTSTEIN, Jaime (Clube de Engenharia). Em Defesa da Engenharia Brasileira. Rio de Janeiro: Engenharia, 1966.

SINICON. Ata da Reunião de Fundação do Sinicon. 10 de março de 1959. Rio de Janeiro: Sinicon, 1959.

SINICON. Estatuto Social e Regulamento Eleitoral. Rio de Janeiro: Sinicon, 2004.

SINICON. Informe Sinicon. Edição de 6 de fevereiro de 1984, n 1, ano I. Rio de Janeiro: Sinicon, 1984 (1984A).

SINICON. Informe Sinicon. Edição de 23 de abril de 1984, n 9, ano I. Rio de Janeiro: Sinicon, 1984 (1984B).

SINICON. Portal eletrônico do Sinicon. Endereço <http://www.sinicon.org.br/>, acessado em 20 de agosto de 2007.

SINICON. Registro de Filiações ao Sindicato. Rio de Janeiro: Sinicon, s/d [obtido através de visita à entidade em 14 de maio de 2010]

SOUSA, Nair Heloísa Bicalho de. Operários e Política: estudo sobre os trabalhadores da construção civil em Brasília. Dissertação de mestrado em Ciências Sociais. Brasília: UnB, 1978.

WAINER, Samuel. Minha Razão de Viver: memórias de um repórter. 10ạ ed. Rio de Janeiro: Record, 1988 [1987]. 